\title{
RISK AND RESILIENCE IN ASIAN MEGACITIES
}

\author{
Guest editorial \\ Markus Keck and Benjamin Etzold
}

Megacities in developing countries are regarded as global risk areas (KRAAs 2008). Due to the concentration of daunting numbers of people, their unprecedented growth rates, their complexities and dynamism, and not least due to the harsh socioeconomic fragmentation, these agglomerations are seen as one of the major challenges of contemporary urbanization (KraAs 2010). ${ }^{1)}$ From a development perspective, the concern is about an expected loss of urban governability, the uncontrolled spread of informality, crime and violence, and the inexorable increase of social marginalization, deprivation and vulnerability (BRONGER 2004; SATTERTHWAITE 2005; KraAs and MERTins 2008).

Megacities in the Global South are highly paradox agglomerations. These paradoxes appear in places where neo-classical villas, high-rise office buildings in concrete and glass and posh shopping complexes stand shoulder to shoulder with hundreds of tiny barracks with corrugated sheet roofs, cobbled together with paperboard, timber and plastic bags (DAVIS 2006). Such conditions might be read as the somewhat bumpy take-off of a slow but steady journey toward development and modernization. For the very people at the margins, though, these circumstances primarily mean a daily struggle for survival. Whether it is the flooding of slums (see the contribution of Tibor Assheuer, Insa Thiele-Eich and BOrIS BRAUn in this volume), poor urbanites' daily

1) This fact is reflected in a number of interdisciplinary research programs that work on the topic since 2005, among them "Risk Habitat Megacity" (German Helmholtz Association), "Emerging Megacities: Research for the Sustainable Development of the Megacities of Tomorrow" (German Ministry of Education and Research, BMBF), "Megacities-Megachallenge: Informal Dynamics of Global Change" (German Research Foundation, DFG), "Urbanization and Global Environmental Change" (International Human Dimensions Program, IHDP), "Urban Resilience" (Resilience Alliance), and most recently "North-South-Network on Urban Self-Organization. Public Life in Europe, India and China" (EU). struggles over access to public space (see the contribution of KIRSTEN HACKENBROCH), terrorist attacks against religious sanctuaries (see the contribution of Linus STROTHMAnN), the expropriation of farmers for the sake of infrastructure development (see the contribution of ANNA LENA BERCHT), or urban livelihoods curtailed by globally rising food prices (see the contribution of Markus Keck and Benjamin ETZOLD); risks in contemporary megacities are manifold and diverse. These risks, that first and foremost hit the urban poor, are often too small to be recognized by a wider public audience. And yet, they have tremendous effects on the livelihoods of the affected people.

The aim of this special issue is to identify those capacities that strengthen people's social resilience. So far, the global challenge of megacities has often been reduced to questions of cities' population size and growth rates, or to their exposure to natural hazards and available funds for adaptive measures. In these cases questions of access, distribution and participation were left widely unnoticed. In contrast to such "de-politicized" perspectives, the contributors of this special issue place an explicit emphasis on the social construction of risks and resilience and focus predominantly on power asymmetries that pervade urban societies, on daily processes of marginalization and exclusion, as well as on people's potentialities to resist and to change present relations. With a focus on the megacities of Dhaka (Bangladesh), Guangzhou (China), and Lahore (Pakistan), the guiding questions of all presented papers are:

- What risks have emerged in contemporary megacities in Asia and for whom are they relevant?

- How do different socio-economic groups and actors perceive these risks, how do they handle them, and how do they adjust themselves in the long run?

- How can we support people's social resilience in order to build more sustainable, more secure, and more just cities? 
The first contribution of this special issue is an introduction to the topic of social resilience. The paper of Markus Keck and Patrick Sakdapolrak provides a comprehensive overview of recently published studies on this issue. It introduces an actor-oriented approach to the subject matter and shows ways ahead in social resilience research. The paper starts with a short summary of the development paths of resilience thinking in social-ecological studies, and continues with identifying key capacities that constitute social resilience, i.e. social actors' capacities to cope, their capacities to learn and adapt, and their capacities to participate and transform. The literature review shows that, today, social resilience is not only a dynamic and relational concept, but also a deeply political one. For the analysis of social resilience, empirical studies have so far focused mainly on network structures and social capital, on institutions and power relations, as well as on knowledge and discourses. KECK and SAKDAPOLRAK argue that the future task of social resilience research lies in acknowledging the role of space by paying more attention to human-environment couplings, socio-spatial interdependencies and translocal feedback loops.

The second contribution of this special issue is an empirical study that deals with the ability of slum dwellers to cope with the impacts of severe floods in Dhaka, Bangladesh. The authors Tibor ABheuer, Insa Thiele-Eich and Boris Braun put special emphasize on how social capital enables poor urbanites to access financial and non-financial support from their neighbors, relatives, landlords, or NGOs. The empirical case study rests on a survey in five flood-affected slum settlements in Dhaka. In November and December 2009, 625 households were interviewed, who experienced at least one severe flood in their immediate environment in recent years. The study shows that internalized norms, reciprocity, enforceable trust and bounded solidarity are main motivational reasons for those people who provide support to people in need during severe flood events. From the perspective of the addressees of the social support it was found that important help is provided by people who live outside of the affected neighborhoods. This explains the practice of "social introduction" between different communities and confirms the importance of structural holes for the building of social resilience.

The role of public space for the livelihoods of the urban poor is the topic of the third contribution of this special issue. Kirsten Hackenbroch presents the changing geographies of risk and uncertainty in a slum settlement in Dhaka (Bangladesh) and discusses the role of informal negotiations for subaltern urbanites to access public places. HACKENBROCH draws a distinction between "risk" as the vulnerability of the poor and marginalized that needs to be accepted when performing livelihood activities, and "uncertainty" as the vulnerability that is created and strategically used by power brokers and hegemonic actors within the urban arena. Based on ethnographic fieldwork, she shows that the urban poor's "resistance power" is rather limited in Dhaka, where social space is dominated by patronage relations and by power brokers who have strong linkages with political parties. As such, the study confirms the importance to include power relations in the study of social resilience and can be read as a plea for being more sensitive in regard to the role of space that - especially in urban settings - becomes the arena where social relations are inscribed and continuously negotiated.

In the fourth article LinUS STROTHMANN looks at specific risks in public space, too. He investigates Pakistan's largest Sufi shrine in the megacity of Lahore (Pakistan) and asks whether this sacred site is a place of risk or rather a place of comfort for the city dwellers. In 2010, more than 50 people were killed at the shrine in a terrorist attack. This shock could, however, not hamper the belief of the visitors and the faith of those people who maintain the shrine and provide welfare services to others. Based on the insights gathered through 150 interviews and participatory observation, Strothmann shows that due to the efforts of volunteers and faith-based organizations and due to its religious significance and symbolic meaning, the shrine continued to be a spiritual refuge and its crucial function as a space of social welfare could be maintained. He argues that the Sufi shrine plays a significant part for maintaining social resilience, as the sanctuary helped people to overcome their trauma and to dispel their fear.

It is the psychology of risk and resilience that stands at the center of the fifth article by Anna Lena Bercht on "Resilience in the Face of Changing Living Conditions in Guangzhou, China - Insights and Perspectives from Psychology". In Guangzhou spatial expansion and infrastructural mega-developments fuelled by intercity competition go hand in hand with a rapid restructuring of peri-urban lives and landscapes. Drawing on her findings from 62 qualitative interviews and solicited photography, BЕRCHT looks at (former) farmers 
who are exposed to the risk of losing their land, their homes and their livelihoods. The study shows that the coping behavior of the farmers and their psychological resilience to this stress differ remarkably, depending on the experience and perceptions of risks, on personal attitudes as well as on means of emotional self-regulation. In her contribution BERCHT differentiates between occupational, emotional and cognitive resilience. She thereby broadens the conventional perspectives in geographical studies of vulnerability and resilience (not only in megacities) with insights from psychology.

In the final contribution of this special issue, Markus Keck and Benjamin Etzold investigate three actor groups and their role in maintaining food security in Dhaka (Bangladesh) - namely wholesale traders, street food vendors, and poor consumers. The authors show that all actors are well equipped to deal with various types of risks. Thanks to wholesale traders' diverse and flexible supply networks there was always enough food in Dhaka despite the fact that the megacity's supplies were repeatedly disconnected due to floods and cyclones. Hawkers and street vendors managed to distribute prepared food throughout the city despite large-scale eviction drives on part of the interim government, and even the urban poor found ways to endure the recent crisis of rising food prices. Nevertheless, the state of Bangladesh not only ignores the role of the mentioned actors, it even works against them. For instance, as the government's food aid schemes proved to be largely ineffective during the food crisis, the most vulnerable people were left alone in the very situation in which governmental support would have been needed the most. As such, KECK and ETZOLD show that building resilience for the urban poor is not (yet) on the agenda of Bangladesh's central government.

Some of the papers in this special issue were presented at the 2010 European Conference of Modern South Asian Studies (ECMSAS) in Bonn in a panel on "Megacities in South Asia as Arenas of Risks and Resilience". Other contributions are based on research projects that were carried out within the Priority Program "Megacities Megachallenge: Informal Dynamics of Global Change". At this point we want to thank the organizers of the ECMSAS conference and express our gratitude to the German Research Foundation (DFG) for supporting our research. Last but not least we are thankful to the editors and the editorial team. This special issue would not have been possible without their flexibility and support.

\section{References}

Bronger, D. (2004): Metropolen. Megastädte. Global Cities. Die Metropolisierung der Erde. Darmstadt.

Davis, M. (2006): Planet of slums. London.

KraAs, F. (2008): Megacities as global risk areas. In: MARZLUFF, J.; Endlicher, W.; Alberti, M.; Bradley, G.; Ryan, C.; ZumBrunnen, C. and Simon, U. (eds): Urban ecology. An international perspective on the interaction between humans and nature. New York, 583-596.

- (2010): Urbanisierung als weltweite Herausforderung. In: Debiel, T.; Messner, D.; Nuscheler, F.; Roth, M. and Ulbert, C. (eds.): Globale Trends 2010. Frieden, Entwicklung, Umwelt. Frankfurt, 181-199.

KraAs, F. and Mertins, G. (2008): Megastädte in Entwicklungsländern: Vulnerabilität, Informalität, Regier- und Steuerbarkeit. In: Geographische Rundschau 60 (11), 4-10.

SATTERTHWAite, D. (2005): The scale of urban change worldwide 1950-2000 and its underpinnings. Human Settlements Discussion Paper Series. International Institute for Environment and Development (IIED), London. http://www.iied.org/pubs/pdfs/9531IIED.pdf (accessed: 10.09.2008)

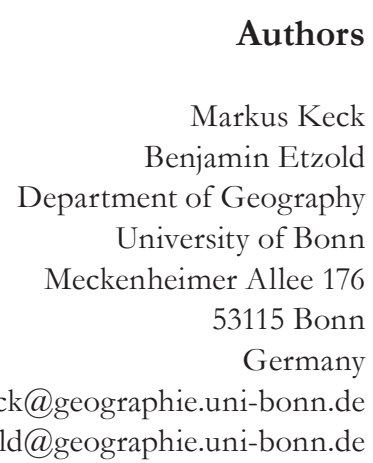

Authors

Benjamin Etzold

ment of Geography

University of Bonn

53115 Bonn

Germany

markus.keck@geographie.uni-bonn.de etzold@geographie.uni-bonn.de 